\title{
Argument, Civility, and Inclusion: Contemporary Uses of Media
} Steven G Woods*

Department of Communication, Western Washington University, USA

Coming from a debate background, the idea of disagreement is a very normal and acceptable concept. Even outside of the competitive realm of tournament competition, the idea that conflict is not negative is an idea embraced by the field of Communication. Conflict is not pejorative in the sense that identifying and working through differences will lead to a superior outcome. Conflict allows people to voice their and their ideas rather than simply conform; the absence of conflict can lead to group think or the imposition of the strongest will rather than the best ideas. In many ways our very society and government are born out of conflict, the desire to express one's self in a state of freedom, not bound by the beliefs of others. Our society is also set up to promote conflict by allowing for free speech and providing space for civic engagement and participation. However, that is the idealized form of conflict, the simple acknowledgement of difference, and the belief that those expressions of difference will lead to discussion, exchange, and ultimately at least shared understanding and mutual respect if not an outcome born from consensus. In recent practice as played out in the media, conflict has become a means to prevent advancement of discussion and consensus. It has become a form of unchallengeable self-expression that is a means of identifying ones infallible and unmovable position along with those that are worthy as true believers, and those that hold a different opinion are just wrong, thus justifiably excluded and devalued.

Coming up through the ranks in teaching many of us have shared the ritual of teaching the basic public speaking course. One of the fundamental elements I sought to share with my classes was the idea that public speaking was a radical political concept in terms of democracy and citizen participation. A nation that trains its people to speak is also training them to speak out, to be active and engaged in their society, and is investing in freedom and democracy. Of course I also emphasized that having something to say in terms of meaningful content was also a part of that social contract. Utilizing evidence, being transparent in the sources of your supporting materials, and respecting your audience are all a part of the package as well. It seems that lesson is not part of the training of those participating in public discourse today.

Is media the $4^{\text {th }}$ estate which serves a public information function, or is it an entertainment outlet, or both? The polarization of viewpoints, the use of code words to both identify audiences and exclude others from being valued or participating is rampant. Viewpoints are more trademarks and commodities than reasoned reflections on events. While the informational value aspects of this glut of presentation is low, audiences are still flocking to these talking heads as viewers and listeners behaviors are driven more by the goals of self-affirmation of belief rather than discovery. This has created the belief in a zero sum world where compromise of opinion is viewed as the equivalent of a personal material loss. Self affirming uses and gratifications of media emphasize the individual as the only unit worth benefit or value, and social or community gains are losses to the individual and their well being. The only arguments one needs to find valid are the ones that support their own opinions and material standing in a vacuum, not in the context of the society and relationships they are a part of.
The effects of this use of information to affirm ones beliefs instead of inform ones beliefs makes selfish actions more justified and appropriate. This fragmentation amongst individuals may mimic a society when viewed externally due to the presence of large numbers of persons, but the discourse reveals marginalization and exclusion as the actual relationship of those individuals, not a society. The feeling that one must be their own special interest in response to the feeling everyone else is acting in their own self interests has led to a decrease in discourse focused on unifying and connecting people. It has led to a distinct desensitization of extreme forms of rhetoric as one group can feel legitimate in devaluing another because they are a threat, or that the other group represents ideas so different from themselves that they do not even have to be considered as part of legitimate society. These polarized and personalized realities allow sides to accuse each other of a lack of civility without having to question their own words. Persons do not see their own lack of civility when the accusations are directed at them by persons they feel not deserving of a civil interaction in the first place because of where the lines have been drawn in an overly polarized public media space. Compromise is seen as moral failure rather than community enriching. The arguments of those with differing viewpoints are easily dismissed when the only information people have sought simply supports what they already believe.

As communication and media scholars are we to simply study this condition and explain it, or study this condition for the purpose of addressing it? Is media the cause, or the reflection of these attitudes and behaviors? Is the turn to news being a reflection of what people want to hear simply a choice that a free market and a right to freedom will produce? To what extent is the responsibility to serve the public a function of the press in a political sense versus the corporate or economic function of profit? To what extent can media be blamed or held accountable given what we understand to be receiver responsibility on the part of the consumer? To what extent does the first amendment make such behavior unquestionable in the political sphere? How can we examine and judge speech that is free, but not conducive to democratic means?

As new media emerges and traditional media transforms culture is becoming more tied to, and immersed in, a mediated world. As media carries so much information and social building power, and since media dictates what information is and how it is obtained, issues that were once only in the political realm now matter significantly

*Corresponding author: Steven G Woods, Department of Communication, Western Washington University, USA, Tel: 360.650.4879; E-mail: steven.woods@wwu.edu

Received February 01, 2012; Accepted February 01, 2012; Published February 03, 2012

Citation: Woods SG (2012) Argument, Civility, and Inclusion: Contemporary Uses of Media. J Mass Communicat Journalism 2:e115. doi:10.4172/2165-7912.1000e115

Copyright: @ 2012 Woods SG. This is an open-access article distributed under the terms of the Creative Commons Attribution License, which permits unrestricted use, distribution, and reproduction in any medium, provided the original author and source are credited. 
to communication studies. Media literacy is fundamentally political literacy in our age. Our connection as a discipline to the understanding of the means and processes of media production may now dictate value laden questions about what media is (or what it "means"), along with what it should be. No longer is the effect of media simply an issue of conveyor of ideas, or transfer of ideas, but rather the actual structure and membership of society is an outcome of media production. How media functions to advantage some and marginalize others is one aspect that needs ongoing examination. How media functions from these aspects clearly need engaged as we transform to participants in a contract carried out by social media rather than participants in a social contract. The issue of civility, the way we treat others at the center of our disputes, is at the core of decoding this fragmentation and polarization of human relations. The ways we are transforming from citizens in a social contract to producers of social media without a contract with each other has real implications for the well being of our political and human community. 